\title{
Sacubitril/Valsartan: Potential Impact of ARNi "Beyond the Wall" of ACE2 on Treatment and Prognosis of Heart Failure Patients With Coronavirus Disease-19
}

\author{
Speranza Rubattu ${ }^{1,2 *}$, Giovanna Gallo ${ }^{1}$ and Massimo Volpe ${ }^{1,2}$ \\ ${ }^{1}$ Cardiology Unit, Department of Clinical and Molecular Medicine, School of Medicine and Psychology, Sant'Andrea Hospital, \\ Sapienza University of Rome, Rome, Italy, ${ }^{2}$ Istituto di Ricovero e Cura a Carattere Scientifico Neuromed, Pozzilli, Italy
}

Keywords: COVID-19, natriuretic peptide, ARNi, cardiovascular diseases, HFrEF-heart failure with reduced ejection fraction

\section{INTRODUCTION}

From the beginning of the SARS-CoV-2 pandemia, the type 2 angiotensin-converting enzyme (ACE2), probably the most "unloved and neglected" member of the renin-angiotensin-aldosterone (RAAS) family, has attracted increasing attention since it has been shown as the cell receptor through which the virus enters into the cells (1).

The physiological action of ACE2, a membrane protein expressed in the heart, lungs,

OPEN ACCESS

Edited by:

Guido laccarino,

University of Naples Federico II, Italy

Reviewed by:

Michele Ciccarelli,

University of Salerno, Italy

*Correspondence:

Speranza Rubattu

rubattu.speranza@neuromed.it

Specialty section:

This article was submitted to

Hypertension,

a section of the journal

Frontiers in Cardiovascular Medicine

Received: 14 October 2020

Accepted: 06 November 2020

Published: 27 November 2020

Citation:

Rubattu S, Gallo G and Volpe M (2020) Sacubitril/Valsartan: Potential Impact of ARNi "Beyond the Wall" of ACE2 on Treatment and Prognosis of

Heart Failure Patients With

Coronavirus Disease-19.

Front. Cardiovasc. Med. 7:616564.

doi: 10.3389/fcrm.2020.616564 kidneys, liver, and intestine, consists in degrading angiotensin II (Ang II) to angiotensin (1-7), a heptapeptide with a potent vasodilator function through the Mas receptor able to counterbalance the Ang II effects on vasoconstriction, sodium retention, and fibrosis (1). Previous studies have shown that Ang II type 1 receptor (AT1R) blockers (ARBs), ACE inhibitors (ACEI), and mineralocorticoid receptor antagonists (MRA) may up-regulate the expression of ACE2 both in acute and chronic settings of cardiovascular diseases (CVDs), such as hypertension, heart failure (HF) and myocardial infarction (1). These data have generated concern during the early phases of the pandemia, since it has been speculated that the increase in ACE2 level may have contributed to disease virulence and to adverse outcomes particularly in subjects affected by chronic coexisting conditions, namely hypertension, coronary artery disease, HF, and diabetes, who commonly received treatment with RAAS inhibitors and who were characterized by a worse clinical course (2).

On the other hand, it has been observed that the binding between coronavirus and ACE2 leads to ACE2 downregulation, resulting in an unopposed production of Ang II by ACE, contributing to lung damage as a consequence of AT1R mediated inflammation, fibrosis, thrombosis, vasoconstriction, and increased vascular permeability. According to these findings, RAAS inhibitors and, in particular, ARBs may even protect against COVID-19 acute lung injury (1). As a matter of fact, epidemiological studies conducted in large populations of COVID-19 patients demonstrated that ARBs or ACE inhibitors had no association with a severe or fatal course of the disease (3-5).

\section{EVIDENCE SUPPORTING THE POTENTIAL BENEFICIAL ROLE OF ARNi IN HF PATIENTS WITH COVID-19}

Natriuretic peptides (NPs), which include atrial natriuretic peptide (ANP), brain natriuretic peptide (BNP), and C-type natriuretic peptide (CNP), along with their N-terminal counterparts, may play an important protective role in COVID-19 disease. NPs are released as a consequence of increased volume overload and myocytes stress and, through their vasorelaxant, diuretic, and 
effects, are able to counterbalance RAAS and sympathetic nervous system actions, ultimately regulating blood pressure, electrolytes, and water homeostasis (6). At the vascular level, NPs reduce cellular growth and proliferation, preserving endothelial function and integrity as well as vascular tone, and they oppose blood clotting, inflammation, angiogenesis, and atherosclerosis progression (6). Apart from their well-described systemic hemodynamic and autocrine/paracrine functions within the cardiovascular system, NPs also play an important protective role in the lungs. In fact, ANP reduces lung endothelial permeability caused by inflammation and oxidative stress, avoiding the development of acute respiratory distress syndrome and improving arterial oxygenation during mechanical ventilation (7). According to this evidence, it has been proposed that COVID-19 patients with deficiencies in the NP system, mainly obese subjects and black people, may have an increased risk of developing severe lung complications.

Of interest, a bidirectional interaction between NPs, particularly ANP, and ACE2 has been demonstrated in experimental models. ANP, through cyclic guanosine monophosphate (cGMP) production, inhibited the Ang II-mediated activation of the extracellular signal regulated kinase (ERK1/ERK2) pathway and upregulated the mitogenactivated protein kinase phosphatase (MKP1), finally preventing the decrease in ACE2 mRNA synthesis (8). On the other hand, Ang-(1-7), the product of ACE2 activity, stimulated ANP secretion through the Mas receptor/phosphatidylinositol 3-kinase/protein kinase B (Mas/PI3K/Akt) pathway, thus reducing cardiac hypertrophy and fibrosis and potentially avoiding COVID-19 pulmonary damage (8).

Furthermore, consistently with the well-known prognostic role of NPs, it has been demonstrated that NT-proBNP level represents an independent risk factor of in-hospital death in patients with severe COVID-19, its levels being significantly higher among those patients who experienced severe clinical conditions, and increasing further during hospitalization in subjects who died, without significant changes among survivors (9).

Apart from the known pathogenetic, diagnostic, and prognostic implications in the cardiovascular system (10), NPs have relevant therapeutic properties. In this context, a field of great interest may be represented by the potential impact on the clinical course of the COVID-19 disease

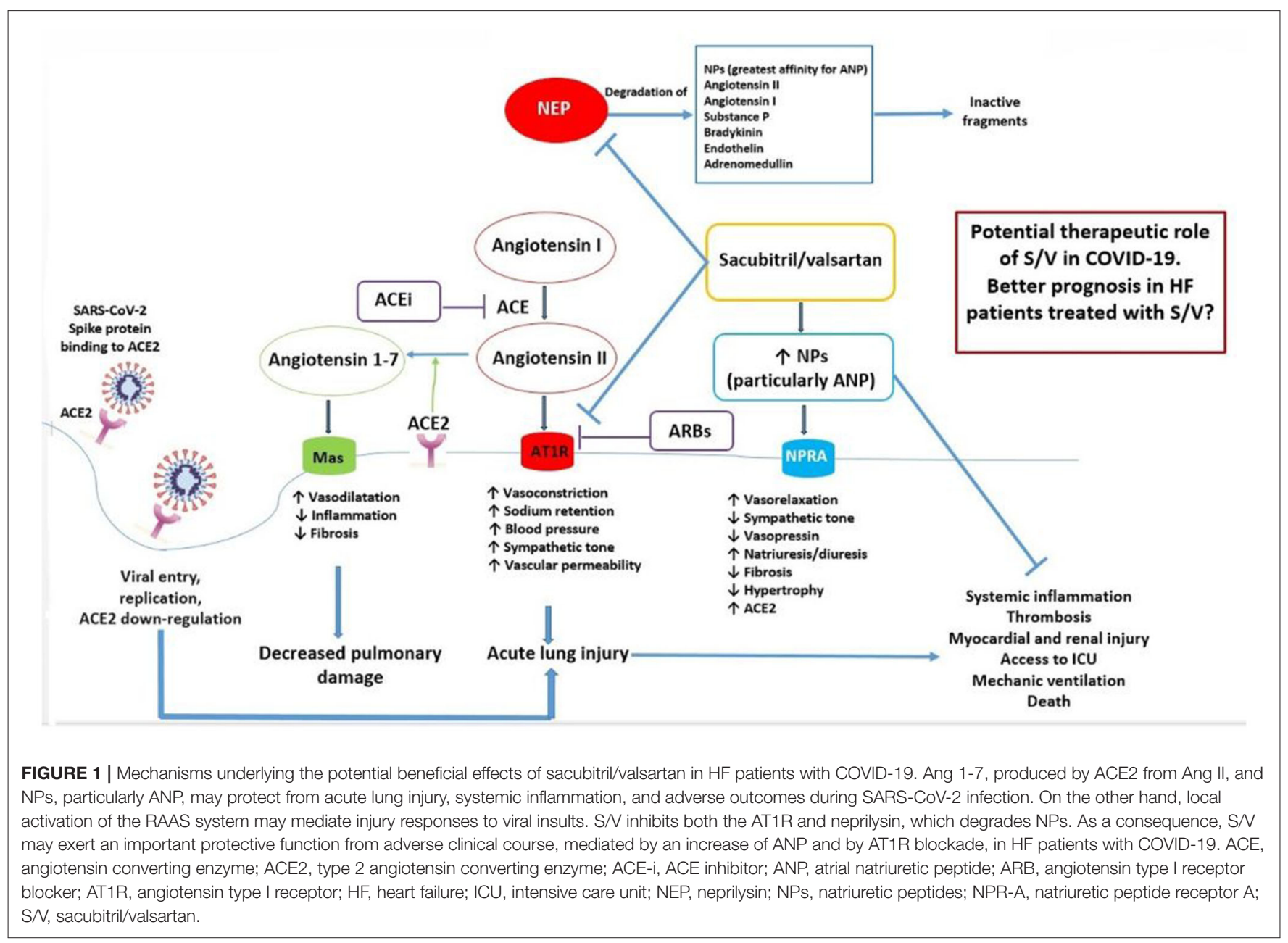


and on its outcome of a treatment with sacubitril/valsartan $(\mathrm{S} / \mathrm{V})$, a member of the new pharmacological class of AT1R/neprilysin inhibitors (ARNi). $\mathrm{S} / \mathrm{V}$ is now recognized as a cornerstone of the therapeutic management of HF with reduced ejection fraction (HFrEF) due to the impressive benefits on cardiovascular death and $\mathrm{HF}$ hospitalization (11).

The beneficial effects of $\mathrm{S} / \mathrm{V}$ in HFrEF were confirmed in recent real-life clinical studies showing a significant reduction of cardiac death and $\mathrm{HF}$ rehospitalization, an improvement of echocardiographic parameters, such as left ventricular EF, systolic volume, and systolic pulmonary arterial pressure, of renal function and of quality of life (1214). Moreover, S/V treatment can be safely started during hospitalization in daily clinical practice with no evidence of increased risk of hypotension, worsening of renal function and hyperkalaemia (15).

With regard to the trend of different NPs levels after the initiation of S/V, NT-proBNP level decreases as a consequence of the improvement of cardiac function and haemodynamic status, representing a useful biomarker of treatment response; BNP level slightly increases due to its relatively low affinity to neprilysin, whereas ANP level consistently and substantially increases both in human studies and in experimental models, mediating most of the benefits of neprilysin inhibition $(16,17)$.

According to these evidences, an approach based on early administration of $\mathrm{S} / \mathrm{V}$ has been proposed in the therapeutic management of all COVID-19 hospitalized patients to avoid an adverse clinical course (18).

\section{REFERENCES}

1. Battistoni A, Volpe M. Might renin-angiotensin system blockers play a role in the COVID-19 pandemic? Eur Heart J Cardiovasc Pharmacother. (2020) 6:248-51. doi: 10.1093/ehjcvp/pvaa030

2. Volpe M, Battistoni A, the board of the Italian Society of Cardiovascular Prevention, Bellotti P, Bellone S, Bertolotti M, et al. Recommendations for cardiovascular prevention during the Sars-Cov-2 pandemic: an executive document by the board of the Italian society of cardiovascular prevention. High Blood Press Cardiovasc Prev. (2020) 30:1-5. doi: 10.1007/s40292-020-00401-1

3. Mancia G, Rea F, Ludergnani M, Apolone G, Corrao G. Renin-angiotensinaldosterone system blockers and the risk of Covid-19. N Engl J Med. (2020) 382:2431-40. doi: 10.1056/NEJMoa2006923

4. Iaccarino G, Grassi G, Borghi C, Ferri C, Salvetti M, Volpe M, et al. Age and multimorbidity predict death among COVID-19 patients: results of the SARS-RAS study of the Italian society of hypertension. Hypertension. (2020) 76:366-72. doi: 10.1161/HYPERTENSIONAHA.120. 15324

5. Volpe M, Battistoni A. Systematic review of the role of renin-angiotensin system inhibitors in late studies on Covid-19: a new challenge overcome? Int J Cardiol. (2020) 321:150-4. doi: 10.1016/j.ijcard.2020.07.041

6. Volpe M, Rubattu S, Burnett J Jr. Natriuretic peptides in cardiovascular diseases: current use and perspectives. Eur Heart J. (2014) 35:41925. doi: 10.1093/eurheartj/eht466

7. Mitaka C, Hirata Y, Nagura T, Tsunoda Y, Amaha K. Beneficial effect of atrial natriuretic peptide on pulmonary gas exchange in patients with acute lung injury. Chest. (1998) 114:223-28. doi: 10.1378/chest.114.1.223

\section{PERSPECTIVES}

Based on the ability of S/V to increase ANP level while antagonizing the Ang II/AT1R effects, we propose a major protective role of this class of drugs in HFrEF patients, the only current indication for the use of ARNi, when affected by COVID19 disease (Figure 1). In order to test the expected beneficial role of S/V in COVID-19, a retrospective analysis of existing registries of hospitalized COVID-19 patients could help to find out whether, among subjects affected by HFrEF, those who were already treated with S/V presented a lower disease incidence, better prognosis, and clinical course (particularly in terms of intensive care unit access, mechanical ventilation, and death), compared to patients who received other medications, including ACEI/ARBs. Furthermore, a call to action is requested to test the potential benefits of S/V in HFrEF patients affected by COVID-19 through new prospective randomized clinical trials.

\section{AUTHOR CONTRIBUTIONS}

SR, GG, and MV contributed to the conception and design, acquisition of data, or analysis and interpretation of data, drafted the article, and approved the final version to be published. All authors contributed to the article and approved the submitted version.

\section{ACKNOWLEDGMENTS}

This manuscript has been released as a pre-print at Authorea 2020 (19).

8. Gallagher PE, Ferrario CM, Tallant EA. Regulation of ACE2 in cardiac myocytes and fibroblasts. Am J Physiol Heart Circ Physiol. (2008) 295:23739. doi: 10.1152/ajpheart.00426.2008

9. Gao L, Jiang D, Wen XS, Cheng XC, Sun M, He B, et al. Prognostic value of NT-proBNP in patients with severe COVID-19. Respir Res. (2020) 21:83. doi: 10.1186/s12931-020-01352-w

10. Rubattu S, Volpe M. Natriuretic peptides in the cardiovascular system: multifaceted roles in physiology, pathology and therapeutics. Int J Mol Sci. (2019) 20:E3991. doi: 10.3390/ijms20163991

11. McMurray JJ, Packer M, Desai AS, Gong J, Lefkowitz MP, Rizkala AR, et al. Angiotensin-neprilysin inhibition versus enalapril in heart failure. $N$ Engl J Med. (2014) 371:993-1004. doi: 10.1056/NEJMoa1409077

12. Polito MV, Silverio A, Rispoli A, Vitulano G, Auria F, De Angelis E, et al. Clinical and echocardiographic benefit of sacubitril/valsartan in a realworld population with HF with reduced ejection fraction. Sci Rep. (2020) 10:6665. doi: 10.1038/s41598-020-63801-2

13. Mentz RJ, Xu H, O’Brien EC, Thomas L, Alexy T, Gupta B, et al. PROVIDE-HF primary results: patient-reported outcomes investigation following initiation of drug therapy with entresto (sacubitril/valsartan) in heart failure. Am Heart J. (2020) 230:35-43. doi: 10.1016/j.ahj.2020.09.012

14. Spannella F, Marini M, Giulietti F, Rosettani G, Francioni M, Perna GP, et al. Renal effects of sacubitril/valsartan in heart failure with reduced ejection fraction: a real life 1-year follow-up study. Intern Emerg Med. (2019) 14:128797. doi: 10.1007/s11739-019-02111-6

15. López-Azor JC, Vicent L, Valero-Masa MJ, Esteban-Fernández A, GómezBueno M, Pérez Á, et al. Safety of sacubitril/valsartan initiated during hospitalization: data from a non-selected cohort. ESC Heart Fail. (2019) 6:1161-6. doi: 10.1002/ehf2.12527 
16. Rubattu S, Cotugno M, Forte M, Stanzione R, Bianchi F, Madonna M, et al. Effects of dual angiotensin type 1 receptor/neprilysin inhibition vs. angiotensin type 1 receptor inhibition on target organ injury in the stroke-prone spontaneously hypertensive rat. J Hypertens. (2018) 36:190214. doi: 10.1097/HJH.0000000000001762

17. Ibrahim NE, McCarthy CP, Shrestha S, Gaggin HK, Mukai R, Szymonifka J, et al. Effect of neprilysin inhibition on various natriuretic peptide assays. J Am Coll Cardiol. (2019) 73:1273-84. doi: 10.1016/j.jacc.2018.12.063

18. Acanfora D, Ciccone MM, Scicchitano P, Acanfora C, Casucci G. Neprilysin inhibitor-angiotensin II receptor blocker combination (sacubitril/valsartan): rationale for adoption in SARS-CoV-2 patients. Eur Heart J Cardiovasc Pharmacother. (2020) 6:135-6. doi: 10.1093/ehjcvp/pvaa028

19. Rubattu S, Gallo, Volpe M. Sacubitril/valsartan: potential impact of ARNi "beyond the Wall" of ACE2 on treatment and prognosis of heart failure patients with COVID-19. Authorea. [Preprint]. (2020). doi: 10.22541/au.160157528.86277450

Conflict of Interest: The authors declare that the research was conducted in the absence of any commercial or financial relationships that could be construed as a potential conflict of interest.

Copyright (c) 2020 Rubattu, Gallo and Volpe. This is an open-access article distributed under the terms of the Creative Commons Attribution License (CC BY).

The use, distribution or reproduction in other forums is permitted, provided the original author(s) and the copyright owner(s) are credited and that the original publication in this journal is cited, in accordance with accepted academic practice. No use, distribution or reproduction is permitted which does not comply with these terms. 